\title{
Cambio de cobertura y uso de suelo en la llanura costera asociados a procesos antropogénicos: caso San Blas, Nayarit
}

\author{
Change of coverage and land use in coastal plain associated with \\ anthropogenic processes: case San Blas, Nayarit
}

\author{
Areli Nájera González', Fátima Maciel Carrillo González*, Julio César Morales Hernández \\ Oyolsi Nájera González²
}

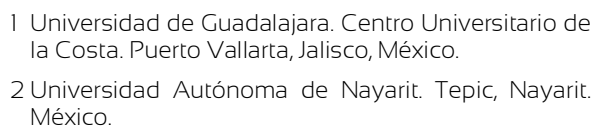

\author{
* Autora de correspondencia. \\ fatima.carrillo@academicos.udg.mx
}

\section{RESUMEN}

Los cambios de uso de suelo generados por el desarrollo de actividades humanas han acelerado la pérdida de cobertura vegetal. Por su ubicación en las llanuras costeras, la cobertura de manglar ha sido una de las más afectadas en los últimos años. Los principales cambios se han evidenciado por actividad acuícola, agropecuaria y turismo. La pérdida de manglar trae como consecuencia modificaciones del clima a escala local, lo que repercute en variaciones del ciclo hídrico y balance salino de las lagunas costeras, propiciando un efecto dominó sobre la biodiversidad, los suelos y por ende las actividades económicas. El presente trabajo tuvo como objetivo evaluar el cambio de cobertura y uso de suelo de la llanura costera de San Blas, Nayarit, del periodo 2000-2019 y su tendencia para el 2038. El método empleado fue la clasificación supervisada de imágenes satelitales en un sistema de información geográfica y la herramienta cadenas de Markov para la proyección futura. Se encontró aumento de áreas de camaronicultura de 4.3\%, lo que llevó al desplazamiento de zonas inundables, posiblemente asociado a impactos en el sistema hídrico, provocando una reducción de la cobertura manglar de 4.7\%, sin embargo, se prevé que la tendencia continuará en menor magnitud para el 2038. Se espera que esta conclusión sea referente para las decisiones futuras sobre el desarrollo de actividades antropogénicas en esta área y otras de llanura costera.

PALABRAS CLAVE: cadenas de Markov, camaronicultura, clasificación supervisada, costa del Pacífico, manglar, proyección futura.

\section{ABSTRACT}

The changes in land use generated by the development of human activities have accelerated the loss of vegetation cover. Due to its location on coastal plains, mangrove coverage has been one of the most affected in recent years. The main changes have been made evident by aquaculture, agriculture, and tourism. The loss of mangrove swamps entails changes in the climate at the local scale, which affects variations in the water cycle and the saline balance of the coastal lagoons, inciting a domino effect on biodiversity, soils, and therefore economic activities. The objective of this work was to evaluate the change in coverage and land use of the coastal plain of San Blas, Nayarit from the period 2000-2019 and its trend for 2038. The method used was the supervised classification of satellite images in a GIS and the Markov chains tool for future projection. An increase in areas for shrimp farming was found (4.3\%), which led to the displacement of flood zones, possible associated with impacts on the hydrologic system, causing a reduction in mangrove cover (4.7\%), however, it is expected that the trend will continue to a lesser extent up to 2038. This conclusion is expected to be a reference for future decisions on the development of anthropogenic activities in this area and others in the coastal plain.

KEYWORDS: Markov chains, shrimp farming, supervised classification, Pacific coastal, mangrove, future projection. 


\section{INTRODUCCIÓN}

El estudio de las causas y consecuencias del cambio de coberturas, así como del uso de suelo es uno de los temas primordiales de investigación a escala internacional. Las discusiones señalan que las actividades humanas son los principales detonantes del cambio en la cobertura vegetal, lo que impacta en el equilibrio natural de los ecosistemas y recursos naturales. Alteraciones del ciclo hídrico, erosión y disminución de calidad de suelos, son algunas de las implicaciones directas que conlleva la pérdida de cobertura vegetal (Morales, Carrillo, Farfán y Cornejo, 2016).

En materia de cambio climático, las coberturas vegetales son vitales en la regulación de la temperatura, por lo tanto, las transformaciones de cobertura vegetal a usos antropogénicos inciden en la variabilidad del clima a nivel local y regional con repercusión mundial (Brovkin et al., 2006; Morales et al., 2016). Las recomendaciones del Panel Intergubernamental de Cambio Climático [IPCC] (2014), priorizan la ejecución de estrategias y políticas públicas para la conservación de la cobertura vegetal como un mecanismo de adaptación y disminución de vulnerabilidad a los efectos del cambio climático.

Entre las coberturas vegetales denominadas centinelas frente al cambio climático, se encuentran los manglares debido a su adaptabilidad a las variaciones ambientales y a los beneficios que ofrece en el mantenimiento del sistema costero y para el uso humano, tales como: estabilidad de la línea de costa, fijación de nutrientes en el suelo, control de calidad de agua, distribución de materia orgánica al océano, nicho de biodiversidad, aprovechamiento forestal, reproducción de especies para acuicultura, sustento de la productividad marina y protección frente a tormentas tropicales, entre otros (Yáñez-Arancibia, Twilley y LaraDomínguez, 1998; Berlanga-Robles y Ruiz-Luna, 2006; Yáñez- Arancibia, Day, Twilley y Day, 2014).

Por su ubicación en la interfaz tierra mar, los manglares forman parte del paisaje fisiográfico llanura costera. Como lo explican González et al. (2009), la llanura costera es una zona baja colindante con el mar, influenciada por la precipitación, la descarga de ríos y la amplitud de mareas.
Se conforma geomorfológicamente por deltas o llanuras aluviales; humedales, tales como: manglares, lagunas costeras y marismas; y barras costeras. Estas características permiten la distribución de otras coberturas vegetales como selva mediana y baja subcaducifolia, matorral espinoso y palmar. Además, dotan a la llanura costera de suelos fértiles propicios para el desarrollo de actividades agropecuarias, la acuacultura, los asentamientos humanos y el turismo, lo que pone en riesgo la cobertura vegetal.

De acuerdo con las referencias, a escala mundial, las actividades antrópicas son las mayores responsables del cambio de cobertura y uso de suelo en las zonas costeras, principalmente las de producción acuícola (MartínezCórdova, Martínez y Cortés-Jacinto, 2009; Rodríguez, Chiriboga y Lojan, 2016), siendo los esteros y manglares las coberturas más afectadas. En México, de 1981 al 2005 se perdió $9.5 \%$ de la cobertura manglar y cerca de $8 \%$ de los esteros y marismas (Valderrama et al., 2014). Algunos autores estiman una tasa anual de pérdida de manglar entre $5 \%$ y $12 \%$ según las distintas regiones del país (López y Ezcurra, 2002).

El caso de la llanura costera de San Blas en Nayarit no es distinto, esta zona es colindante con el área natural protegida llamada Reserva de la Biosfera Marismas Nacionales en el Pacífico Mexicano, sin embargo, no se encuentra dentro del decreto de protección, lo que ha propiciado su aprovechamiento, sin un correcto orden a falta de planes de manejo (Valdez, 2004). Antecedentes desde 1973 reflejan que la zona ha sufrido cambios de cobertura debido a la agricultura, las granjas camaronícolas y el uso urbano. La cobertura más afectada ha sido la selva baja, la cual perdió la mitad de su extensión en el periodo 1973-1992, con tasas de deforestación anual en aumento desde 1986, seguida de las zonas de manglar estimando $20 \%$ de pérdida para 2001 por construcción de estanquería para el cultivo de camarón. Aunque para el 2013 el impacto directo de la camaronicultura sobre el manglar fue menor a $10 \%$, la transformación mayor se dio en las planicies de inundación con 36\%, lo que termina impactando indirectamente al conjunto de manglar y humedales por la interrupción de la conectividad entre ambos (Berlanga- 
Robles y Ruiz-Luna, 2006; Berlanga-Robles, García, LópezBlanco y Ruiz-Luna, 2010; Berlanga-Robles, Ruiz-Luna, Bocco y Vekerdy, 2011; Berlanga-Robles y Ruiz-Luna, 2013; Lithgow, De la Lanza y Silva, 2019).

Entender las causas y dinámicas del cambio de cobertura y uso de suelo son esenciales para revertir las tendencias negativas a través del establecimiento de estrategias, para el manejo y protección de las llanuras costeras (Berlanga-Robles et al., 2011). Para ello, la percepción remota es una técnica que facilita, desde una perspectiva gráfica y continua, la identificación de transformaciones de la cubierta terrestre, relacionadas con la dinámica vegetal y los usos antropogénicos a través del tiempo y el espacio (Berlanga-Robles y Ruiz-Luna, 2006).

El presente trabajo es un aporte de continuidad a las investigaciones previas en la llanura costera de San Blas, Nayarit. Los resultados fueron obtenidos por medio de técnicas de percepción remota, imágenes de satélite y uso de sistema de información geográfica [SIG], actualizando la información de los años 2000 y 2019 y su tendencia para el 2038.

\section{OBJETIVOS}

Elaborar mapas de cobertura y uso de suelo de los años 2000 y 2019, por medio de la interpretación de imágenes de satélite; validar los mapas de cobertura y uso de suelo de los años 2000 y 2019 a través del cálculo de exactitud global e índice Kappa; analizar los cambios de cobertura y uso de suelo en el periodo 2000-2019, de acuerdo con la tasa de cambio anual, valores de pérdida, ganancia, cambio neto, transición y permanencia; estimar la cobertura y uso de suelo para el año 2038, resultado de una matriz de probabilidad de cambio (Markov) y su proyección cartográfica; relacionar de forma descriptiva los cambios de cobertura y uso de suelo del periodo 2000-2019 con los procesos antropogénicos en la zona.

\section{MATERIALES Y MÉTODOS}

\section{Área de estudio}

La llanura costera de San Blas (Fig. 1) es la fracción del área que compone el paisaje fisiográfico conocido como Llanura Costera del Pacífico, que está dentro de los límites del municipio de San Blas, Nayarit. De acuerdo con la información cartográfica del Instituto Nacional de Estadística y Geografía [negi] (2000), se ubica entre las coordenadas $21.7^{\circ}$ y $21.4^{\circ}$ Latitud Norte y $-105.5^{\circ}$ y $-105.1^{\circ}$ Longitud Oeste, colindando al sur con la sierra del Eje Neovolcánico y al norte con el caudal y desembocadura del río Santiago. El área total comprende $371.1 \mathrm{~km}^{2}$, representando $45 \%$ del territorio municipal, con abundantes cuerpos de agua, alimentados mayormente por la cuenca Huicicila y que son importantes para la conservación como superficie estuarina con vegetación de mangle del área de la Tovara, decretada como región hidrológica prioritaria (RHP-23 San Blas-La Tovara), sitio Ramsar en 2008 por la Comisión Nacional de Áreas Naturales Protegidas [Conanp] y proyectada como Área de Protección de Flora y Fauna Terrestre con referente en lo publicado en el Diario Oficial de la Federación [DOF] (2008). Por estas características geográficas, también es una área fértil importante para la producción agrícola y acuícola del estado (González et al., 2009).

En el área se concentra 45.6\% de la población total del municipio, distribuido en 13 asentamientos humanos: San Blas como cabecera municipal, Aután, Guadalupe Victoria, Santa Cruz, Aticama, Huaristemba, Matanchen, El Corte, El Carleño, Playa los Ramírez, Boca de Asadero, Las Islitas y Playa los Cocos (Inegi, 2010).

\section{Métodos}

Los cambios de cobertura se realizaron a partir de la interpretación de mapas de cobertura producidos por la clasificación supervisada de imágenes de satélite en los años 2000 y 2019, por medio del algoritmo de máxima verosimilitud (maximun likelihood algorithm) (Aldrich, 1997). Este es un método estadístico utilizado con recurrencia para clasificar imágenes satelitales, se alimenta de firmas espectrales generadas previamente a través de campos de entrenamiento seleccionados con el auxilio de datos de campo y otros elementos cartográficos. Los valores de estas firmas espectrales son tomados como parámetros para seleccionar aquellos pixeles de la imagen de satélite con mayor probabilidad de acercarse al valor definido. 


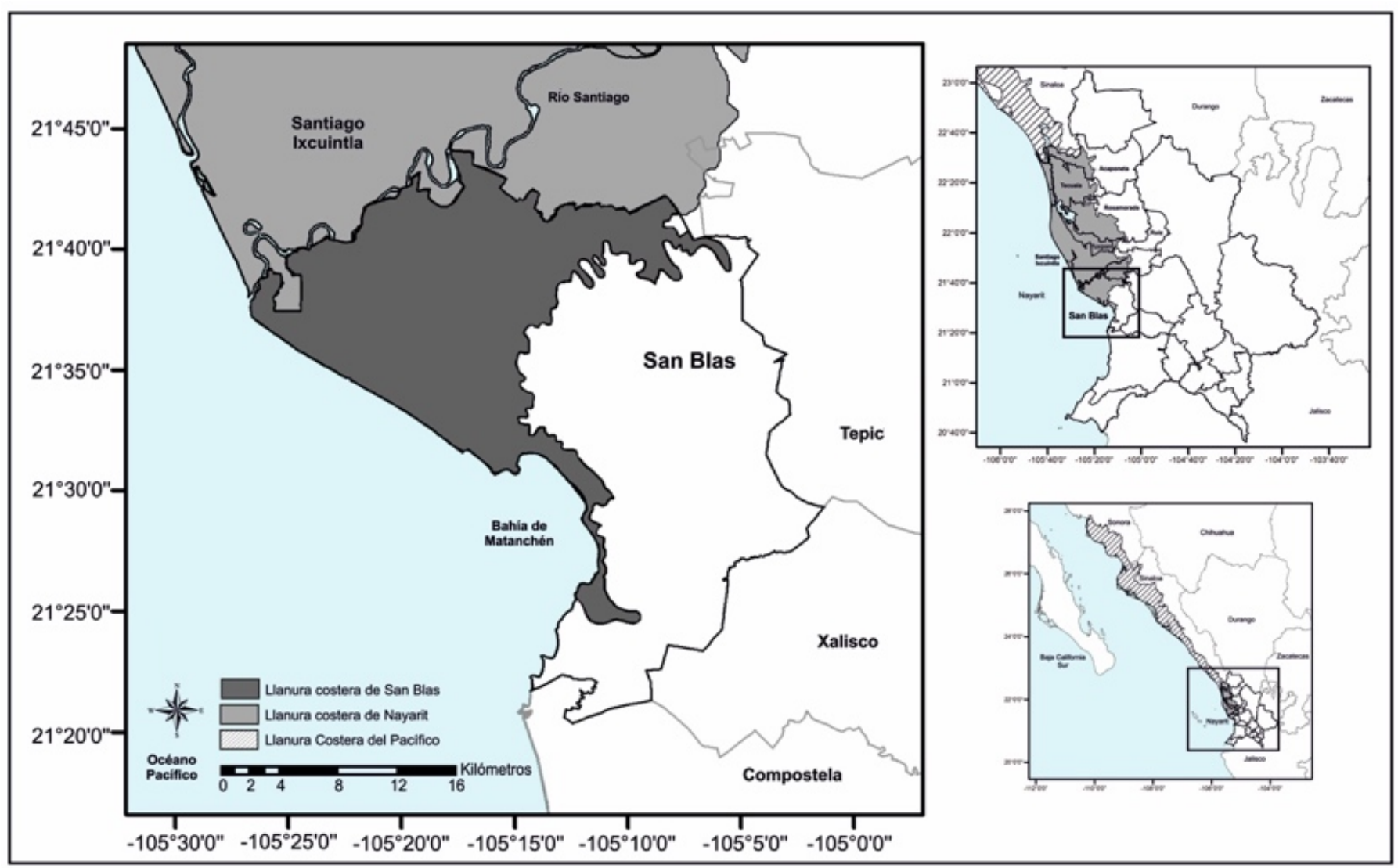

FIGURA 1. Localización del área de estudio llanura costera San Blas, Nayarit.

Información con referencia del mapa temático de fisiografía de Inegi (2000) y González et al. (2009).

Como lo describen Morales et al. (2016), el procedimiento consiste en elegir un grupo de pixeles que representan cada una de las clases determinadas de coberturas y usos de suelo a través de un SIG; el software utilizado fue ArcGIS 9.0. Los grupos de pixeles son llamados campos de entrenamiento, estos fueron puntos elegidos a partir de fotointerpretación de composiciones en falso color, imágenes de la plataforma Google Earth, cartografía digital de vegetación y uso de suelo Serie III (Inegi, 2005) y VI (Inegi, 2017) y observaciones en campo. Mediante los valores de reflectancia de los campos de entrenamiento se genera una firma espectral de cada una de las clases, estas firmas sirven de referencia para que el algoritmo, con base en estadística bayesiana, asigne al resto de los pixeles la probabilidad de pertenecer a cada una de las clases y elige para ellos aquella clase que represente mayor probabilidad.
Se examinaron las imágenes de satélite del mes de mayo por ser época de estiaje, lo que permite resaltar diferencias visuales entre grupos de coberturas de los años 2000 y 2019, obtenidas del Servicio Geológico de los Estados Unidos [USGS] (s/f).

Para el año 2000 se seleccionaron imágenes Landsat 5 Thematic Mapper (TM) compuesta por siete bandas espectrales con los siguientes datos: fecha 28 de mayo del 2000 , cobertura de nubes $36 \%$, ángulo de azimut del sol 84.71, ángulo de elevación del sol 63.05, calidad de imagen 9 sin errores detectados, resolución espacial de 30 metros en bandas reflectivas y 120 metros en infrarrojo térmico, con el sistema de coordenadas WGS84/UTM13N. Y para el año 2019 imágenes Landsat 8 Operational Land Imager (OLI) and Thermal Infrared Sensor (TIRS) compuesta por 11 bandas espectrales con los siguientes datos: fecha 01 de mayo de 2019, cobertura de nubes $6.33 \%$, ángulo de azimut 
del sol 67.19, ángulo de elevación del sol 102.71, calidad de imagen 9 sin errores detectados, resolución espacial 30 metros en bandas reflectivas y térmicas, 15 metros en la banda pancromática, con el sistema de coordenadas WGS84/UTM13N. De ambas imágenes, solo se utilizaron las bandas reflectivas para realizar las composiciones en falso color, con apoyo de la guía de Lillesand, Kiefer y Chipman (2004) y la experiencia en teledetección de manglares de Leija-Loredo, Reyes-Hernández, ReyesPérez, Flores-Flores y Sahagún-Sanchéz (2016).

De acuerdo con los metadatos de las imágenes se consideró buena calidad y similitud de características; exclusión de nubes para la zona del área de estudio, valores similares de ángulo de azimut y ángulo de elevación del sol. Por lo tanto, no fue necesario realizar corrección atmosférica u otras técnicas de procesamiento previas. Las escenas fueron aisladas a partir de un buffer de $5 \mathrm{~km}$ del polígono que marca los límites del municipio de San Blas, en el mapa de la llanura costera de Nayarit publicado por González et al. (2009). La intención del buffer fue poder observar diferencias en la línea de cauce y desembocadura del río Santiago, ya que se tienen antecedentes de variaciones (Berlanga-Robles y Ruiz-Luna, 2006). La clasificación utilizada fue la propuesta por Berlanga-Robles y Ruiz-Luna (2006), modificada por la naturaleza del polígono de estudio a siete grupos de cobertura (Tabla $1 \mathrm{y}$ Fig. 2).

Al mapa obtenido del proceso de clasificación se le realizó una corrección radiométrica. La corrección modifica los valores registrados erróneamente o "ruido" presentes en la imagen. Estos son pixeles con un valor erróneo del cual no puede extraerse información alguna, suelen producirse por problemas durante el proceso de almacenamiento y transmisión en el SIG. Para restablecer el valor correcto del píxel se recurrió a la información de los pixeles circundantes por medio de la herramienta majority filter.

TABLA 1. Clasificación de coberturas y uso de suelo del área de estudio.

\begin{tabular}{|c|c|c|}
\hline & Grupo & Cobertura y uso de suelo \\
\hline 1 & Superficies acuáticas & $\begin{array}{l}\text { Sistemas estuarios, lagunas costeras, canales, cauces de ríos, excluyendo el Océano } \\
\text { Pacífico y estanques de actividad acuícola. }\end{array}$ \\
\hline 2 & Manglar & $\begin{array}{l}\text { Asociaciones de hidrófilas dominadas por especies de manglar (Laguncularia racemosa, } \\
\text { Rhizophora mangle y Avicennia germinans). }\end{array}$ \\
\hline 3 & Zonas inundables & $\begin{array}{l}\text { Marismas con etapas de secas e inundación que pueden presentarse con o sin } \\
\text { vegetación (vegetación hidrófila en asociación con la especie de mangle Conocarpus } \\
\text { erectus). }\end{array}$ \\
\hline 4 & Agricultura & Terrenos agrícolas cosechados o en preparación y áreas de pastoreo. \\
\hline 5 & Vegetación secundaria & $\begin{array}{l}\text { Vegetación segundaría de selva baja y mediana subcaducifolia, asociaciones de } \\
\text { arbustos y vegetación perturbada. }\end{array}$ \\
\hline 6 & Poblados & Asentamientos humanos \\
\hline 7 & Camaronicultura & Estanques de granjas camaronícolas y actividad acuícola en uso y abandonadas. \\
\hline
\end{tabular}



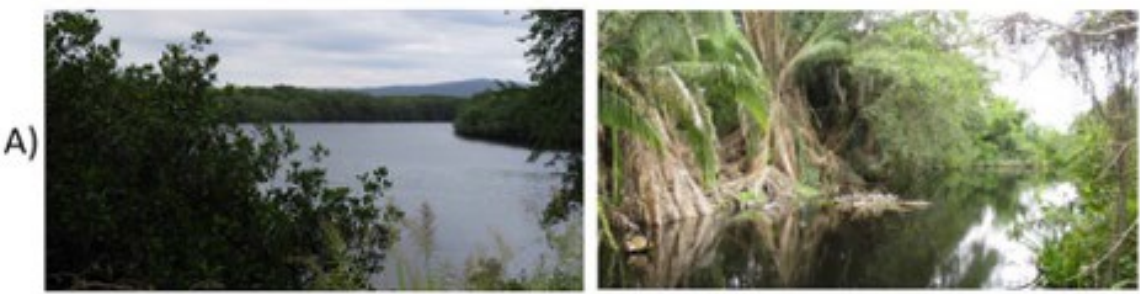

B)
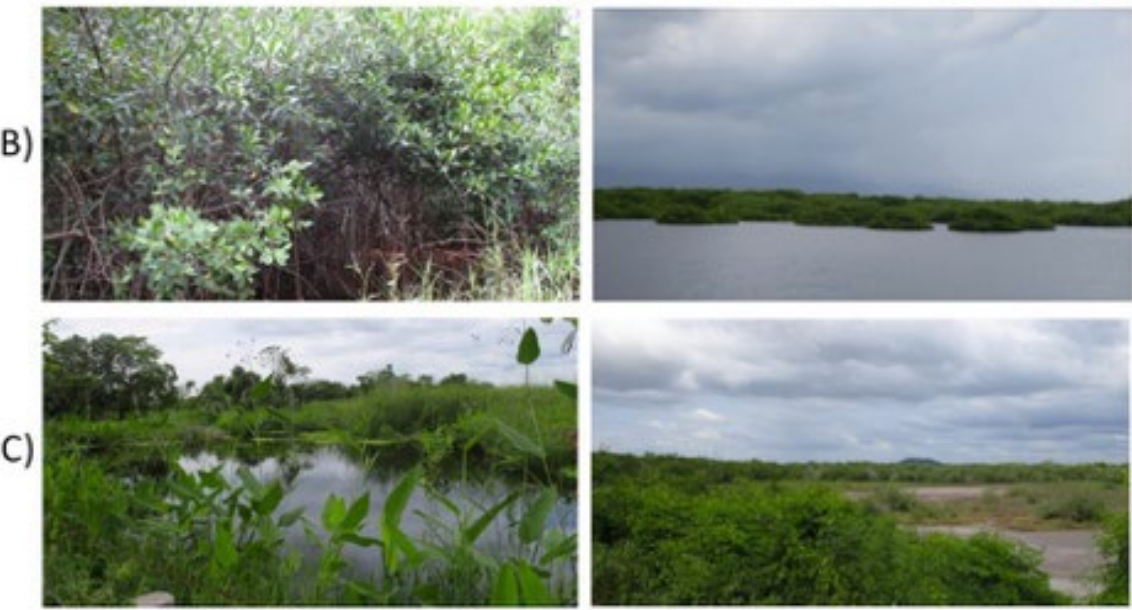

D)
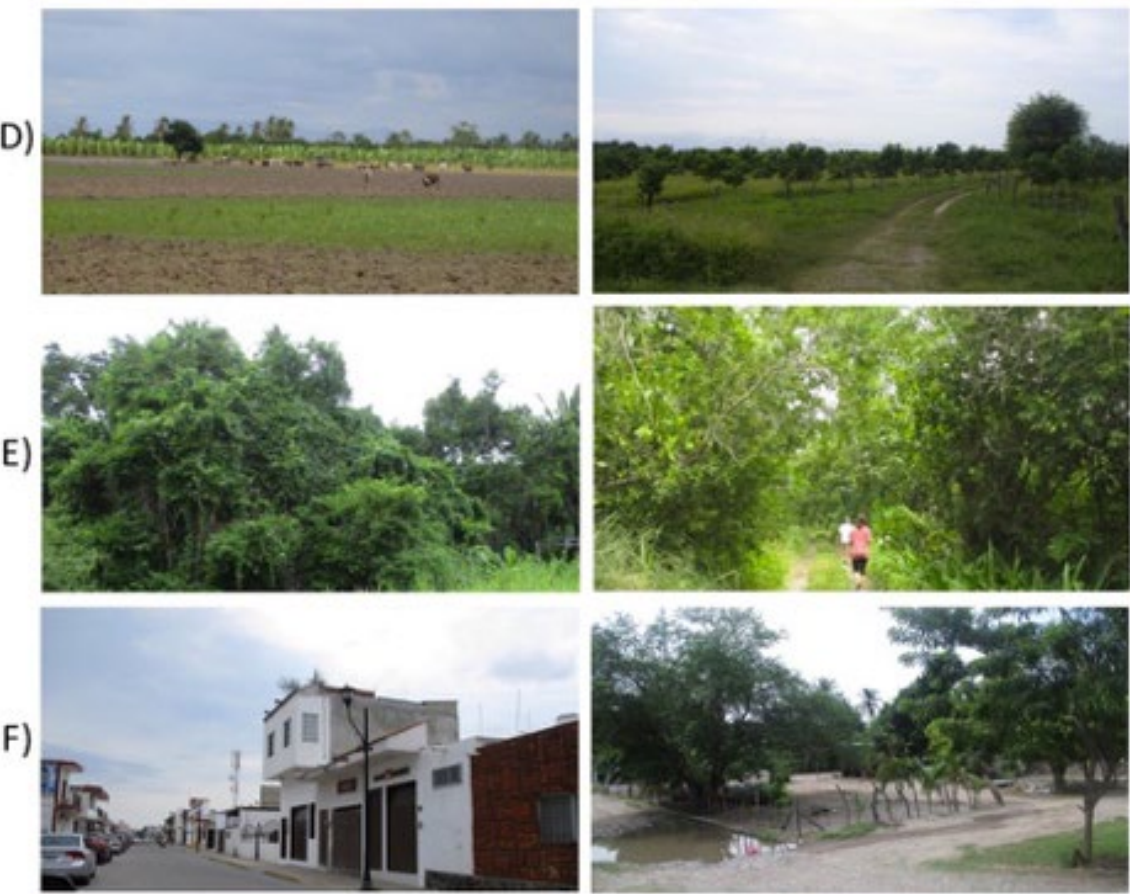

G)
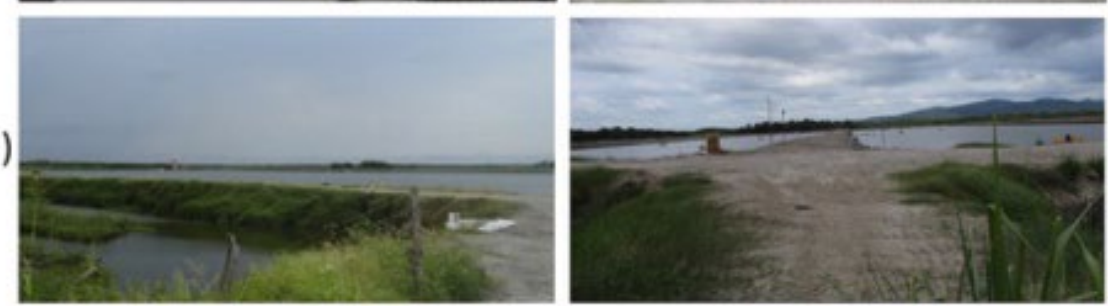

FigURA 2. Fotografías del área de estudio ejemplificando los grupos de cobertura y usos de suelo. A) cuerpos de agua, B) cobertura manglar, C) zonas inundables, D) usos agrícolas, E) vegetación secundaría, F) poblados y G) camaronicultura. 
Se calculó la exactitud total de la clasificación, obteniendo el índice Kappa (Cohen, 1960), con la siguiente fórmula descrita en Morales et al. (2016).

$$
k=\frac{N \sum X_{i i}-\sum\left(X_{i i} * X_{+i}\right)}{N^{2}-\sum\left(X_{i} * X_{+i}\right)}
$$

donde:

k: índice Kappa

$\mathrm{N}$ : total de datos muestreados

$X_{i i}$ : acuerdo observado

$X_{i} * X_{+i}:$ concordancia esperada

El valor obtenido del índice Kappa se interpreta como el nivel de concordancia entre lo observado y el azar, es decir, mide la concordancia entre los datos de la clasificación y los datos de referencia. Sus valores van de 0 a 1 y se representan en porcentajes. Los valores significativamente distintos a 0 indican un proceso de clasificación mejor al resultante del azar; el valor de 1 significa que hay total acuerdo, por lo tanto, entre más se acerque el valor a 1, mayor será la concordancia. Como los criterios difieren entre autores, en este caso se tomó el propuesto por Landis y Koch (1977); valores menores a 0.4 simbolizan concordancia pobre; valores entre 0.4 y 0.8 una concordancia moderada y valores mayores a 0.8 una concordancia fuerte. El valor del índice Kappa es tomado como referencia para medir la exactitud total del mapa generado. A mayor nivel de concordancia significa menor número de errores $\mathrm{y}$, por lo tanto, mayor nivel de exactitud.

Para conocer la confiabilidad de la información clasificada se analizaron las matrices de error como lo describen Berlanga-Robles et al. (2010). En una matriz de error se representa la exactitud de un mapa por cada una de las clases determinadas en la clasificación, estos errores pueden ser por comisión (inclusión de un área en una clase cuando no pertenecía a la muestreada dentro de los campos de entrenamiento) o por omisión (exclusión de un área que fue muestreada dentro de los campos de entrenamiento) pero al final de la clasificación quedó integrada en otra clase.
Con estos datos se calculó la exactitud del productor como el resultado de dividir las unidades clasificadas correctamente, entre el número de unidades muestreadas de cada clase; la exactitud del usuario como el resultado de dividir las unidades clasificadas correctamente de cada clase, entre el número de unidades generadas por la clasificación supervisada; y la exactitud global obtenida dividiendo el total de unidades correctamente clasificadas de todas las clases, entre el número total de unidades muestreadas. Los tres valores se expresan en forma de porcentajes.

Resumiendo lo anterior, la matriz de error es una comparación entre las áreas de las clases generadas en el mapa, a partir de la percepción remota y las áreas de las clases determinadas por alguna información de referencia. La sumatoria de las diferencias entre estas se asume como el nivel de error del proceso de clasificación (Congalton y Green, 1993). Se construyó la matriz de error comparando la información de los mapas resultantes de la clasificación supervisada y la información real, obtenida mediante corroboración en campo y cartografía de referencia.

Como lo sugiere Congalton (1991), se verificaron al menos 50 puntos georreferenciados por grupo de cobertura y uso de suelo. Para el año 2019 se realizaron visitas de campo para la verificación de los resultados. La mayoría de los puntos de verificación fueron elegidos de forma aleatoria simple, en función de la posibilidad de acceso por vía terrestre. Los sitios donde se evidenciaron los cambios por granjas camaroneras se visitaron directamente. Para el año 2000 la mayoría del mapa se verificó con base en la cartografía digital de vegetación y uso de suelo Serie III (Inegi, 2005) y algunos puntos con los resultados obtenidos en Berlanga-Robles y Ruiz-Luna (2006).

Del análisis de los mapas de cobertura y uso de suelo se obtuvo la tasa de cambio anual a través de la ecuación descrita en Ruiz, Savé y Herrera (2013).

$$
\text { Tasa }=\left[\frac{S_{2}}{S_{1}}\right]^{\frac{1}{n}}-1
$$


donde:

$S_{2}$ : superficie de la fecha 2 o fecha final.

$S_{1}$ : superficie de la fecha 1 o fecha base.

$\mathrm{n}$ : número de años entre las dos fechas.

El resultado se expresa en porcentaje

Los valores de pérdida, ganancia, cambio neto, transición y permanencia se calcularon con las fórmulas descritas en Braimoh (2006), a partir de una matriz de tabulación cruzada o matriz de cambio, construida según la metodología propuesta por Pontius, Shusas y McEchern (2004) y descrita con detalle en Gallardo y Martínez-Vega (2012).

$$
l p=\frac{\text { Pérdida }}{\text { Permanencia }}
$$

donde:

\p: relación pérdida/permanencia

Pérdida : superficie de la fecha 1 o fecha base, que se pierde con respecto a la fecha 2 o fecha final y en la matriz de cambios representa los valores en horizontal

Permanencia : superficie de la fecha 1 o fecha base, que se conserva en la fecha 2 o fecha final y en la matriz de cambios representa los valores en diagonal

$$
g p=\frac{\text { Ganancia }}{\text { Permanencia }}
$$

donde:

$g$ : relación ganancia/pernamencia

Ganancia : superficie de la fecha 2 o fecha final, que se gana con respecto a la fecha 1 o fecha base y en la matriz de cambios representa los valores en vertical

Permanencia : superficie de la fecha 1 o fecha base, que se conserva en la fecha 2 o fecha final y en la matriz de cambios representa los valores en diagonal

$$
n p=g p-l p
$$

donde:

$n p$ : relación cambio neto permanencia
La cobertura y uso del suelo es un proceso estocástico donde los cambios están en función del tiempo y dependen del estado inmediato anterior de cambio para su proyección futura, uno de los métodos utilizados para estimar la proyección de cambio a partir de dos fechas es el modelo estadístico de cadenas de Marvok (Balzter, 2000). Una cadena de Markov representa un sistema de elementos que hacen transiciones de un estado a otro a lo largo del tiempo; el número de pasos de tiempo en el pasado influyen en la distribución de probabilidad del estado actual y con esta probabilidad puede ser proyectado el mismo número de pasos de tiempo al futuro.

Dando por hecho lo anterior, la predicción de tendencias de cambio de uso de suelo fue simulada para el año 2038, fecha propicia a proyectar dado a que el número de años que se analizó previamente fue de 19 años.

La predicción se realizó con el procedimiento descrito en Reynoso, Valdez, Escalona, De los Santos y Pérez (2016), el cual emplea dos pasos y un proceso de validación a través de un SIG para realizar la simulación futura, cabe aclarar que el software utilizado fue TerrSet 18.3. Primero, se utilizó el módulo cadenas de Marvok para obtener una matriz de probabilidad de transición con 15\% de margen de error. Posteriormente, se ejecutó el modelo de Markovautómatas celulares con 19 interacciones y un filtro de contigüidad de $5^{*} 5$ píxeles, sin considerar impulsores de cambio adicionales, para generar el mapa de simulación del año 2038. Finalmente, el mapa resultante del año 2038 fue validado generando una simulación para el año 2019, con la misma matriz de probabilidad de transición, teniendo como mapa base el del año 2000, como resultado de la clasificación supervisada. El mapa simulado del 2019 se comparó con el mapa real de la misma fecha, obtenido también de la clasificación supervisada, por medio del módulo validate, el cual proporciona el estadístico Kappa para evaluar dicha similitud.

\section{RESULTADOS Y DISCUSIÓN}

A partir de la clasificación supervisada de imágenes satelitales se obtuvieron dos mapas temáticos de cobertura y uso de suelo, de los años 2000 y 2019 con cuatro 
coberturas: superficies acuáticas, manglar, zonas de inundación y vegetación secundaria; y tres usos de suelo: agricultura, poblados y camaronicultura (Fig. 3). En la validación, ambos obtuvieron un nivel de concordancia moderada: el año 2000 obtuvo 76.4\% de exactitud global y $71.6 \%$ de índice Kappa (Tabla 2) y el año 2019 logró 85.7\% de exactitud global y 82.8\% de índice Kappa (Tabla 3). Tomando como parámetro el rango de Landis y Koch (1977), los mapas obtuvieron una exactitud moderada con relación a la información de referencia. Respecto a la exactitud global, aunque algunos autores señalan que al obtener valores menores a $80 \%$ el proceso se debe repetir, se consideró con mayor relevancia el valor del índice Kappa ya que toma en cuenta todos los elementos de la matriz de error (Mas, 1999).

Las clases manglar y agricultura fueron las de mayor exactitud en ambas fechas, las clases con mayor error fueron superficies acuáticas, zonas inundables y camaronicultura. Esto es similar a los resultados de otras clasificaciones por tratarse de superficies con agua y superficies sujetas a inundación temporal mareal (BerlangaRobles et al., 2010). La exactitud del productor de zonas inundables y exactitud del usuario de camaronicultura en el año 2000 fue muy baja debido a las diferencias entre la clasificación de referencia y la clasificación utilizada, especialmente por un área de granjas camaroneras abandonadas que en los datos de referencia fueron catalogadas como zonas inundables y en los datos de la clasificación como camaronicultura. Cabe señalar que algunos autores consideran como criterio mínimo $70 \%$ de precisión en cada una de las clases para ser considerada una clasificación exitosa (Thomlinson, Bolstad y Cohen,1999).

Los puntos de referencia del año 2019 fueron elegidos al azar en función de la accesibilidad por vía terrestre, esto puede ser tomado como una limitante del valor obtenido para la exactitud del mapa. Las granjas camaroneras y los poblados fueron obtenidos por medio de la clasificación, aunque para algunos autores esto puede ser considerado un error. Para mejorar la precisión se sugiere que los polígonos de estas clases sean digitalizados a parir de un mapa de referencia, e incorporados posteriormente en el mapa resultante de la clasificación (Berlanga-Robles et al., 2010).

Se encontró discrepancia en la extensión de la superficie entre las fechas. En el año 2000 obtuvo una extensión total de 37965.6 ha y en el año 2019 una extensión de 37606.7 ha; observando una disminución de 358.9 ha. De acuerdo con las imágenes de satélite, la diferencia se debe a la variación en la línea de costa hacia la parte noroeste del área de estudio. Esta disminución de superficie terrestre se explica como área ganada por el mar y está relacionada estrechamente con la geomorfología de la zona compuesta por el subpaisaje denominado llanura de inundación mareal alta (González et al., 2009). Las coberturas con pérdida fueron superficies acuáticas de 43.8 ha, manglar de 299.5 ha y zonas inundables de 16.6 ha. Si bien los manglares mantienen la línea de costa (YáñezArancibia et al., 2014), una posible explicación es que se deba a una afectación en el régimen hidrológico de las lagunas costeras por lluvias atípicas, ciclones tropicales y huracanes: directamente el huracán Kena en 2002, e indirectamente el huracán Wila en 2018. Estos fenómenos pudieron haber modificado la intensidad mareal y caudal del río Santiago, causando erosión del suelo y facilitando la caída de los arboles (Ortiz y Pérez, 1999; Tovilla y Orihuela, 2004; Flores-Verdugo, Amezcua, Kovacs, Serano y Blanco, 2014). Según antecedentes, entre 1973 y 1993 el caudal del río Santiago ya había tenido impacto erosivo en la desembocadura con una estimación de pérdida de manglar de 14.8 ha por año (Ortiz y Romo, 1994; Ramírez-García, López-Blanco y Ocaña, 1998; Hernández-Guzmán, RuizLuna y Cervantes-Escobar, 2019). Aunque la cifra de 14.9 ha por año es similar a la observada para este periodo, se sugiere indagar con mayor profundidad el hallazgo, con un estudio detallado de la línea de costa del polígono y zonas convergentes al norte. No se manifestaron cambios en la línea del cause del río Santiago, a diferencia de los antecedentes registrados por Berlanga-Robles y Ruiz-Luna (2006) observados en los años 1973, 1986 y 1992. 

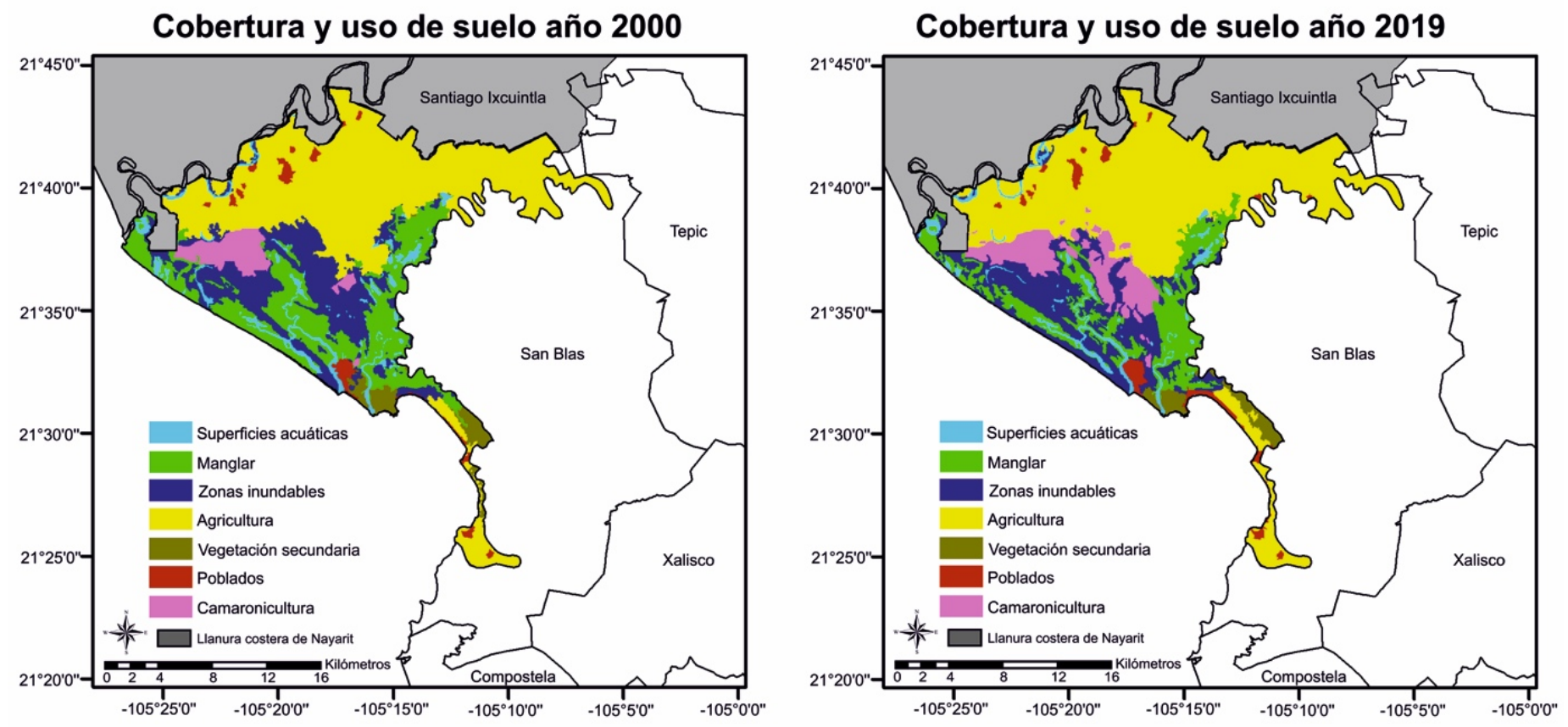

FIgURA 3. Mapa de cobertura y uso de suelo año 2000 y 2019.

TABLA 2. Matriz de error año 2000.

\begin{tabular}{|c|c|c|c|c|c|c|c|c|c|}
\hline \multicolumn{10}{|c|}{ Matriz de error para el año 2000} \\
\hline & \multicolumn{9}{|c|}{ Datos de referencia } \\
\hline & Grupo & $\begin{array}{l}\text { Superficies } \\
\text { acuáticas }\end{array}$ & Manglar & $\begin{array}{c}\text { Zonas } \\
\text { inundables }\end{array}$ & $\begin{array}{l}\text { Agricul- } \\
\text { tura }\end{array}$ & $\begin{array}{l}\text { Vegetación } \\
\text { secundaria }\end{array}$ & Poblados & $\begin{array}{l}\text { Camaroni- } \\
\text { cultura }\end{array}$ & Total \\
\hline \multirow{6}{*}{ 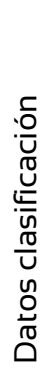 } & Superficies acuáticas & 147 & 103 & 15 & 9 & 0 & 0 & 1 & 275 \\
\hline & Manglar & 3 & 380 & 42 & $\mathrm{O}$ & 1 & $\mathrm{O}$ & $\mathrm{O}$ & 426 \\
\hline & Zonas inundables & 1 & 30 & 201 & 0 & 0 & 0 & 13 & 245 \\
\hline & Agricultura & $\mathrm{O}$ & 1 & 5 & 258 & 4 & 5 & $\mathrm{O}$ & 273 \\
\hline & Vegetación secundaria & $\mathrm{O}$ & 1 & 1 & 1 & 69 & $\mathrm{O}$ & $\mathrm{O}$ & 72 \\
\hline & Poblados & $\mathrm{O}$ & $\mathrm{O}$ & $\mathrm{O}$ & 7 & 5 & 271 & $\mathrm{O}$ & 283 \\
\hline & Camaronicultura & 3 & 7 & 270 & 24 & $\mathrm{O}$ & $\mathrm{O}$ & 460 & 764 \\
\hline & Total & 154 & 522 & 534 & 299 & 79 & 276 & 474 & 2338 \\
\hline & Exactitud productor & $95.5 \%$ & $72.8 \%$ & $37.6 \%$ & $86.3 \%$ & $87.3 \%$ & $98.2 \%$ & $97 \%$ & \\
\hline & Exactitud usuario & $53.5 \%$ & $89.2 \%$ & $82 \%$ & $94.5 \%$ & $95.8 \%$ & $95.8 \%$ & $60.2 \%$ & \\
\hline \multicolumn{10}{|c|}{ Exactitud global= $76.4 \%$} \\
\hline & Índice Kappa= 71.6\% & & & & & & & & \\
\hline
\end{tabular}


TABLA 3. Matriz de error año 2019.

Matriz de error para el año 2019

\begin{tabular}{|c|c|c|c|c|c|c|c|c|c|}
\hline \multicolumn{10}{|c|}{ Datos de referencia } \\
\hline & Grupo & $\begin{array}{l}\text { Superficies } \\
\text { acuáticas }\end{array}$ & Manglar & $\begin{array}{c}\text { Zonas } \\
\text { inundables }\end{array}$ & $\begin{array}{l}\text { Agricul- } \\
\text { tura }\end{array}$ & $\begin{array}{l}\text { Vegetación } \\
\text { secundaria }\end{array}$ & Poblados & $\begin{array}{c}\text { Camaroni- } \\
\text { cultura }\end{array}$ & Total \\
\hline \multirow{10}{*}{ 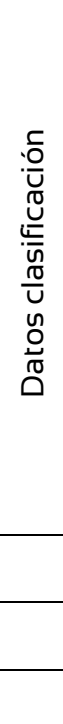 } & $\begin{array}{l}\text { Superficies } \\
\text { acuáticas }\end{array}$ & 159 & 80 & 20 & 6 & 9 & $\mathrm{O}$ & 1 & 275 \\
\hline & Manglar & 0 & 364 & 39 & 7 & 16 & 0 & 0 & 426 \\
\hline & Zonas inundables & 1 & 10 & 179 & 18 & 0 & 0 & 37 & 245 \\
\hline & Agricultura & 0 & 0 & $\mathrm{O}$ & 272 & 0 & 1 & 0 & 273 \\
\hline & $\begin{array}{l}\text { Vegetación } \\
\text { secundaria }\end{array}$ & $\mathrm{O}$ & $\mathrm{O}$ & 3 & 6 & 62 & 1 & $\mathrm{O}$ & 72 \\
\hline & Poblados & $\mathrm{O}$ & 0 & $\mathrm{O}$ & 12 & $\mathrm{O}$ & 271 & 0 & 283 \\
\hline & Camaronicultura & $\mathrm{O}$ & 0 & 14 & 0 & 0 & 0 & 750 & 764 \\
\hline & Total & 160 & 454 & 255 & 321 & 87 & 273 & 788 & 2338 \\
\hline & Exactitud productor & $99.4 \%$ & $80.2 \%$ & $70.2 \%$ & $84.7 \%$ & $71.3 \%$ & $99.3 \%$ & $95.2 \%$ & \\
\hline & Exactitud usuario & $57.8 \%$ & $85.4 \%$ & $73.1 \%$ & $99.6 \%$ & $86.1 \%$ & $95.8 \%$ & $98.2 \%$ & \\
\hline
\end{tabular}

Exactitud global= 85.7\%

Índice Kappa= $82.8 \%$

Se excluyeron las hectáreas de transición al mar para evitar confusión entre los valores descriptivos de las coberturas, el uso de suelo y la matriz de cambios, de tal forma que ambos polígonos tuvieran la extensión de 37606.7 ha, tomando como límite del polígono la línea de costa resultante de la imagen del año 2019.

\section{Cobertura y uso de suelo periodo 2000-2019}

En el año 2000, el uso predominante fue la agricultura con $49.4 \%$, seguido de la cobertura manglar con $19.5 \%$ y las zonas inundables con 17.6\%; en menor extensión la camaronicultura con $4.3 \%$, las superficies acuáticas con $4.1 \%$, la vegetación secundaría con $2.9 \%$ y poblados con 2\%. Para el año 2019 la dinámica se mantuvo similar con algunas variaciones: el predominio de uso agrícola con $52.5 \%$, seguido de zonas inundables con $15.7 \%$ y manglar con $14.8 \%$, con aumento en el uso de camaronicultura con $8.5 \%$ y poblados con $2.6 \%$; con una extensión menor de superficies acuáticas con $3.5 \%$ y de vegetación secundaria con $2.4 \%$.

La mayor tasa de cambio anual positiva fue en el uso de la camaronicultura con $3.7 \%$, los poblados con $1.3 \% \mathrm{y}$ con menor valor la agricultura con $0.3 \%$. En contraparte, la cobertura manglar, las superficies acuáticas y la vegetación secundaria indicaron ser las de mayor porcentaje de cambio anual negativo con $-1.7 \%$, $-1 \%$ y $-0.9 \%$ respectivamente, seguido de las zonas inundables con $-0.6 \%$.

Las mayores transiciones en el periodo se dieron por aumento de la camaronicultura; las zonas inundables se transformaron en granjas camaroneras con 1538 ha, repercutiendo en transición de cobertura manglar como pérdida, a zonas inundables con una ganancia de 1910.9 ha (Fig. 4). 


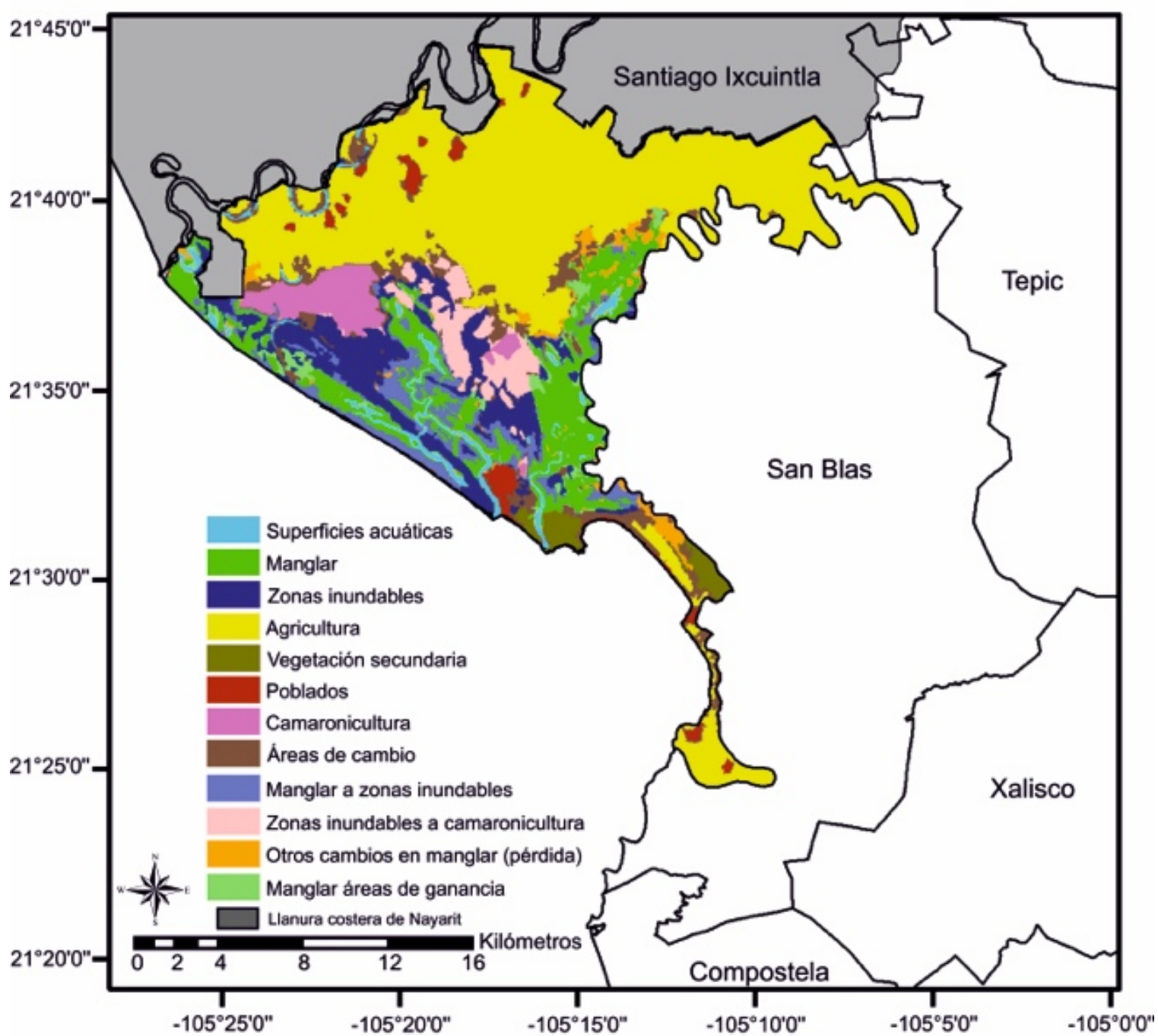

Figura 4. Permanencia y áreas de cambio de cobertura y uso de suelo del periodo 2000-2019.

Las transiciones más notorias fueron de manglar a zonas inundables (1910.9 ha) y de zonas inundables a camaronicultura (1538 ha). Se incluyen otras áreas de pérdida (805.6 ha) y ganancia (860.2 ha) de manglar.

Según lo descrito en Berlanga-Robles y Ruiz-Luna (2013) y Lithgow et al. (2019), las tasas altas de crecimiento de la actividad camaronícola se han mantenido desde periodos atrás en 1990, 2000 y 2013, transformando mayormente áreas de cubierta selvática y manglar durante 1973 y 1990 y áreas de humedales y manglares entre el 2000 y el 2013. Esto último concuerda con los resultados obtenidos para le periodo 2000-2019, donde se observa la transformación de zonas inundables a camaronicultura y de manglar a zonas inundables. A diferencia, la pérdida de vegetación secundaria de selva baja y media fue por transformación de uso agrícola.

Aunque directamente la camaronicultura no está desplazando la cobertura manglar por deforestación como en otros sitios (Martínez-Córdova et al., 2009; BerlangaRobles et al., 2011; Lithgow et al., 2019), de acuerdo con los resultados sí hay afectación de forma indirecta. Posiblemente esto se deba a la redistribución del agua en los canales de las lagunas costeras, que es unos de los impactos más significativo de la actividad camaronícola 
(Rodríguez et al., 2016) y ha sido estudiado en otros sitos de la llanura costera del Pacífico (Berlanga-Robles et al., 2011).

Las granjas camaroneras por sus requerimientos son construidas sobre zonas de marismas, esteros y lagunas que se encuentran conectados por medio de canales que permiten el flujo de agua dulce y salada, variando su nivel de agua y salinidad según las temporadas de lluvia y estiaje, así como las mareas (Martínez-Córdova et al., 2009; Berlanga-Robles et al., 2011). Las coberturas vegetales predominantes en estas zonas son asociaciones de especies de mangle que se distribuyen según la disponibilidad de agua. En el área de estudio se tiene registro de cuatro: mangle rojo (Rhizophora mangle), mangle blanco (Laguncularia racemosa), mangle negro (Avicennia germinans) y mangle botoncillo (Conocarpus erectus) (Valdez, 2002; Valdez, 2004; Comisión Nacional para el Conocimiento y Uso de la Biodiversidad [Conabio], 2007). Por sus características fisiológicas, las asociaciones de mangle blanco, rojo y negro se distribuyen en zonas que se mantienen con agua durante la mayor parte del tiempo (Valdez, 2004), por esta razón en la clasificación propuesta en la investigación, las especies fueron agrupadas en la cobertura manglar. Por el contrario, el mangle botoncillo es capaz de mantenerse en zonas de variación de inundación con etapas secas (Valdez, 2004), razón por la cual fue asignado dentro del grupo de cobertura de zonas inundables en la clasificación.

El incremento de la camaronicultura y con ello la transformación de zonas del sistema estuarino, puede estar repercutiendo en la distribución del recurso hídrico, lo cual se evidencia en las transiciones entre coberturas de manglar y zonas inundables.

Otras transiciones que destacaron por actividad antropogénica fueron la ganancia de agricultura a zonas inundables con 881.6 ha, de manglar con 393.6 ha y de vegetación secundaría con 217.1 ha. Aunque la superficie de poblados aumentó, la transición mayor fue en zonas de uso agrícola con 180.9 ha. Todos los cambios y transiciones entre coberturas y usos se muestran en la tabla 4.

TABLA 4. Matriz de cambio 2000-2019

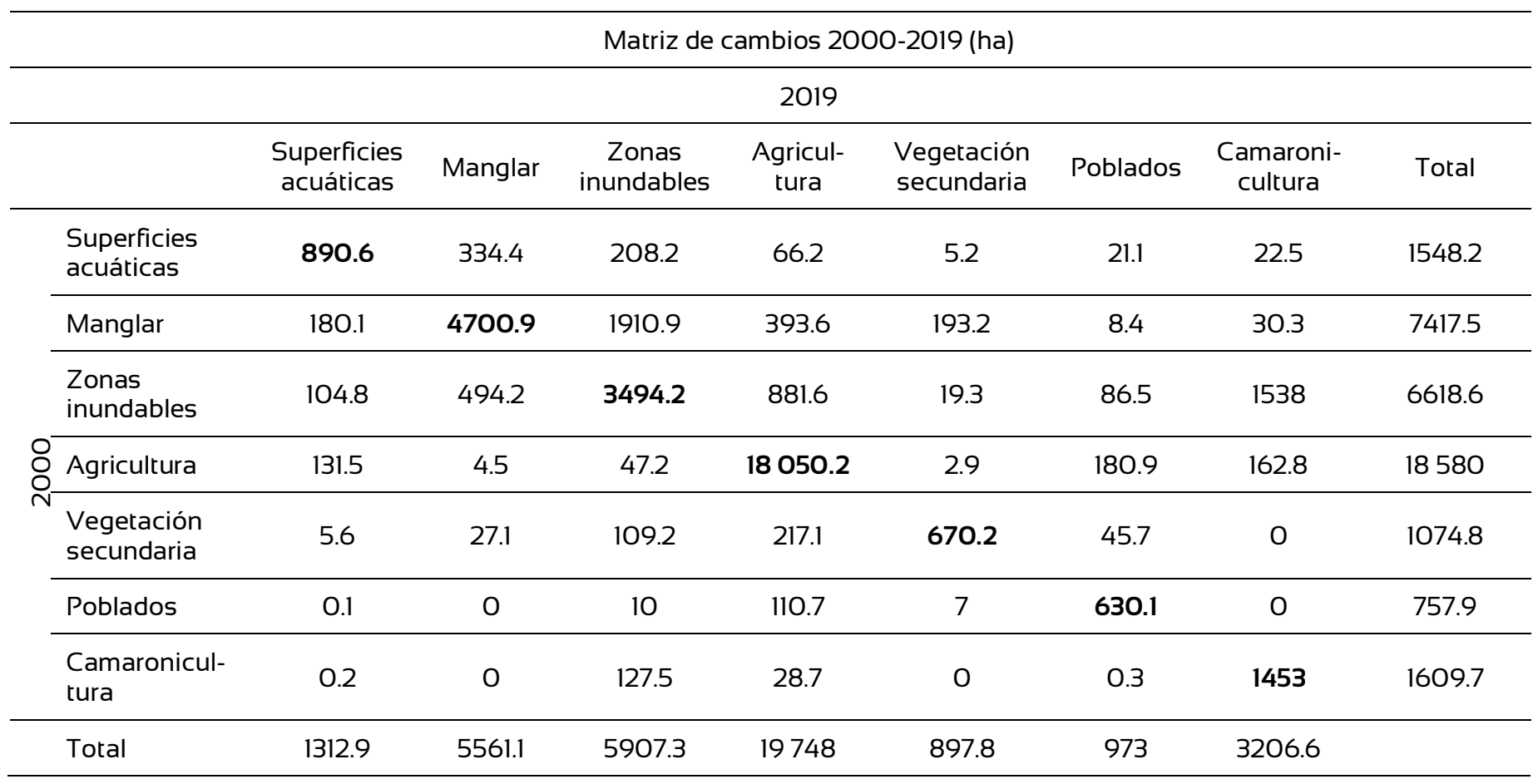

Los valores en diagonal resaltados representan las superficies en hectáreas que permanecen sin cambio entre 2000 y 2019 . Los valores fuera de la diagonal representan las superficies de intercambio durante el mismo periodo. 
Los valores de relación de pérdida, ganancia, cambio neto y permanencia reflejan la misma dinámica (Tabla 5); la cobertura con mayor pérdida en relación de cambio neto permanencia $(n p)$, durante el periodo fue el manglar con $0.4 \mathrm{np}$. A pesar de eso, mantiene un porcentaje de permanencia de $60.9 \%$ y una relación de ganancia permanencia $(g p)$ de 0.2 ; esto equivale a 860.2 ha de ganancia de superficies acuáticas, zonas inundables, agricultura y vegetación secundaria, probablemente resultado de la implementación de prácticas de manejo y programas institucionales (Sanjurjo y Campos, 2011) (Fig. 4).

Las zonas inundables fueron las más cambiantes ya que registraron una permanencia de $52.7 \%$, pero los valores de relación pérdida/permanencia y ganancia/permanencia fueron similares: $0.9 \quad l p$ y $0.7 \quad g p$. La agricultura y camaronicultura permanecieron por arriba de 90\%, la agricultura con poco aumento de $0.1 \mathrm{np}$ y la camaronicultura con el mayor valor de relación ganancia/permanencia de $1.2 \mathrm{gp}$. Se observó una disminución en las superficies acuáticas de $-0.2 \mathrm{np}$, lo cual puede estar relacionado con la variación de temporada de estiaje (Berlanga-Robles y Ruiz-Luna, 2006) y disminución en la vegetación secundaria de $-0.3 \mathrm{np}$, un problema que se manifiesta paulatinamente desde 1990 de acuerdo con lo expuesto en Berlanga-Robles y Ruiz-Luna (2013).

$\mathrm{El}$ incremento de poblados de $0.5 \mathrm{gp}$ fue focalizado en la zona circundante a la Bahía de Mantanchén, desplazando zonas inundables, vegetación secundaría y agrícola por zonas de asentamientos humanos, particularmente de uso turístico. En los últimos diez años se le ha dado impulso al turismo en esta área empezado a comprometer las coberturas vegetales (Ramos, 2015). Tomando como referencia las experiencias en sitos aledaños con características similares (Navarro-Rodríguez, Téllez-López, González y Cruz-Romero, 2010), el turismo sin una correcta planeación podría ser un detonador de cambio importante en un futuro.

Compilando los resultados de transiciones de coberturas y uso de suelo entre 2000 y 2019 en la matriz de probabilidad de cambio Markov 2000-2019, los intercambios con mayor probabilidad fueron de transición de manglar a zonas inundables con 0.26 , zonas inundables a camaronicultura con 0.23 y vegetación secundaria a agricultura con 0.20 (Tabla 6).

TABLA 5. Valores de pérdida, ganancia, cambio neto y permanencia de cobertura y uso de suelo del periodo $2000-2019$.

\begin{tabular}{lcccc}
\hline Grupo & $\begin{array}{c}\text { Relación pérdida } \\
\text { permanencia } \\
l p\end{array}$ & $\begin{array}{c}\text { Relación ganancia } \\
\text { permanencia } \\
g p\end{array}$ & $\begin{array}{c}\text { Relación cambio neto } \\
\text { permanencia } \\
n p\end{array}$ & Permanencia (\%) \\
\hline Superficies acuáticas & 0.7 & 0.5 & -0.2 & $56 \%$ \\
\hline Manglar & 0.6 & 0.2 & -0.4 & $60.9 \%$ \\
\hline Zonas inundables & 0.9 & 0.7 & -0.2 & $52.7 \%$ \\
\hline Agricultura & 0.0 & 0.1 & 0.1 & $97.1 \%$ \\
\hline $\begin{array}{l}\text { Vegetación } \\
\text { secundaria }\end{array}$ & 0.6 & 0.3 & -0.3 & $62.4 \%$ \\
\hline Poblados & 0.2 & 0.5 & 0.3 & $83.1 \%$ \\
\hline Camaronicultura & 0.1 & 1.2 & 1.1 & $90.3 \%$ \\
\hline
\end{tabular}

Los valores de relación pérdida permanencia cercanos a l indican una mayor pérdida que permanencia.

Los valores de relación ganancia permanencia cercanos a l indican una mayor ganancia que permanencia.

Los valores de relación cambio neto permanencia positivos cercanos a l indican una mayor ganancia, los valores negativos cercanos a -1 indican una mayor pérdida. 
TABLA 6. Matriz de probabilidad de cambio de Markov 2000-2019.

\begin{tabular}{lcccccccc}
\hline \multicolumn{7}{c}{ Matriz de probabilidad de cambio (Markov) 2000-2019 } \\
\hline & $\begin{array}{c}\text { Superficies } \\
\text { acuáticas }\end{array}$ & Manglar & $\begin{array}{c}\text { Zonas } \\
\text { inundables }\end{array}$ & $\begin{array}{c}\text { Agricul- } \\
\text { tura }\end{array}$ & $\begin{array}{c}\text { Vegetación } \\
\text { secundaria }\end{array}$ & $\begin{array}{c}\text { Poblad } \\
\text { os }\end{array}$ & $\begin{array}{c}\text { Camaroni- } \\
\text { cultura }\end{array}$ & Total \\
\hline $\begin{array}{l}\text { Superficies } \\
\text { acuáticas }\end{array}$ & 0.58 & 0.22 & 0.13 & 0.04 & 0 & 0.01 & 0.01 & 1.00 \\
\hline Manglar & 0.02 & 0.63 & 0.26 & 0.05 & 0.03 & 0 & 0 & 1.00 \\
\hline $\begin{array}{l}\text { Zonas } \\
\text { inundables }\end{array}$ & 0.02 & 0.07 & 0.53 & 0.13 & 0 & 0.01 & 0.23 & 1.00 \\
\hline $\begin{array}{l}\text { Ogricultura } \\
\text { N }\end{array}$ & 0.01 & 0 & 0 & 0.97 & 0 & 0.01 & 0.01 & 1.00 \\
\hline $\begin{array}{l}\text { Vegetación } \\
\text { secundaria }\end{array}$ & 0.01 & 0.03 & 0.10 & 0.20 & 0.62 & 0.04 & 0 & 1.00 \\
\hline \begin{tabular}{l} 
Poblados \\
\hline $\begin{array}{l}\text { Camaronicul- } \\
\text { tura }\end{array}$
\end{tabular} & 0 & 0 & 0.01 & 0.15 & 0.01 & 0.83 & 0 & 1.00 \\
\hline Total & 0.63 & 0.95 & 1.12 & 1.57 & 0.67 & 0.91 & 1.16 & 1.00 \\
\hline
\end{tabular}

Proyección de cobertura y uso de suelo periodo 2019-2038

Con base en la matriz de probabilidad de cambio de Markov, se estimó que para el año 2038, el uso prevaleciente del área de estudio continúe siendo la agricultura con $55.1 \%$, con poco cambio de $0.02 \%$ en incremento anual; seguido de la actividad camaronícola de $11.9 \%$, siendo la de mayor crecimiento con respecto al 2019 , de $1.8 \%$ de incremento anual.

La cobertura más afectada por disminución sería el manglar, pasando de $14.8 \%$ en 2019 , a $11.4 \%$ estimado en 2038 (-1.4\% en decremento anual). Seguido, las zonas inundables de $15.7 \%$ a $13.7 \%$; las superficies acuáticas de $3.5 \%$ a $3 \%$; y la vegetación secundaria de $2.4 \%$ a $2 \%$ con un decremento anual de $-0.7 \%, \quad-0.8 \%$ y $\quad-0.1 \%$ respectivamente. Los poblados continuarían en aumento con $0.8 \%$ anual. Se espera que esta cifra sea mayor ya que no refleja la posible expansión por actividad turística en la zona cercana al litoral.

En la figura 5 se muestra la representación cartográfica resultante para el año 2038 en el proceso de validación en el que se obtuvo 86\% de índice Kappa. Las transiciones más significantes de 2019 a 2038 resultaron ser de zonas de manglar a zonas inundables con 1432.7 ha y de zonas inundables a camaronicultura con 1372.7 ha (Tabla 7). Los valores de relación pérdida, ganancia, cambio neto y permanencia se presentan en la tabla 8.

\section{Procesos antropogénicos asociados}

Después de la publicación del primer inventario nacional de manglares (Conabio, 2007) y la recategorización de riesgo de las especies de manglares en la NOM-059SEMARNAT-2010 (DOF, 2010), que pasó de protección especial a amenazadas, se incrementaron los esfuerzos de manejo, conservación y restauración de manglar en la zona de estudio y zonas aledañas, (Sanjurjo y Campos, 2011; Blanco, 2012; Comisión Nacional Forestal [Conafor], 2013). Aun así, los resultados obtenidos no demuestran la eficacia esperada y concuerdan con las conclusiones de Flores-Verdugo et al. (2014), quienes exponen que debido a que los esfuerzos se centran en la vigilancia de extracción forestal y en la restauración por medio de propagación y siembra directa de mangle, no se ha considerado que la afectación podría estar sucediendo por los impactos antrópicos en la hidrología de la región. 


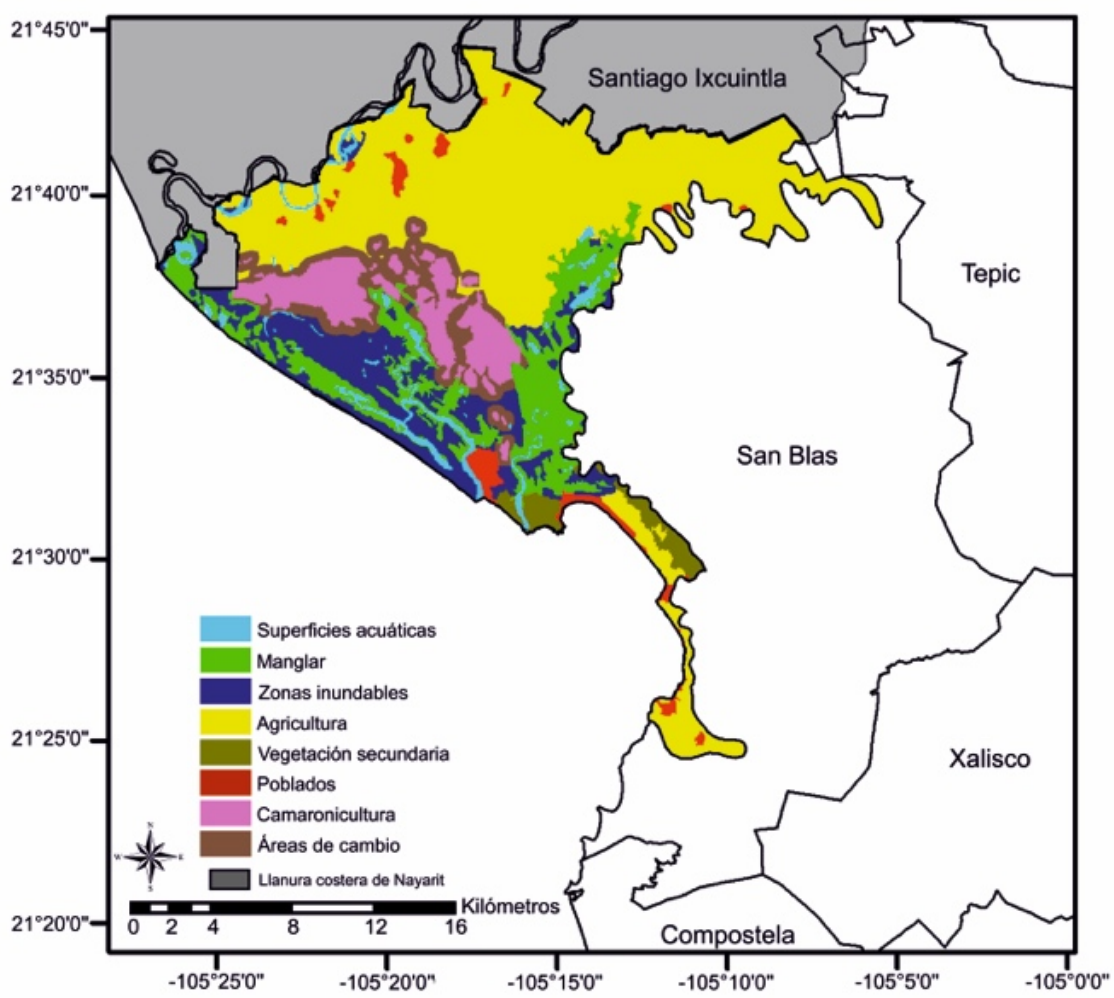

FIGURA 5. Áreas de cambio estimado para el año 2038, las transiciones más notorias fueron de zonas inundables a camaronicultura (1372.7 ha) por aumento de uso camaronícola.

TABLA 7. Matriz de cambios estimados para el periodo 2019-2038

\begin{tabular}{|c|c|c|c|c|c|c|c|c|c|}
\hline \multicolumn{10}{|c|}{ Matriz de cambios 2019-2038 (ha) } \\
\hline & & $\begin{array}{c}\text { Superficies } \\
\text { acuáticas }\end{array}$ & Manglar & $\begin{array}{c}\text { Zonas } \\
\text { inundables }\end{array}$ & Agricultura & $\begin{array}{l}\text { Vegetación } \\
\text { secundaria }\end{array}$ & Poblados & $\begin{array}{c}\text { Camaroni- } \\
\text { cultura }\end{array}$ & Total \\
\hline \multirow{5}{*}{$\frac{\sigma}{\sigma^{-}}$} & $\begin{array}{l}\text { Superficies } \\
\text { acuáticas }\end{array}$ & 755.2 & 283.6 & 176.5 & 56.1 & 4.4 & 17.9 & 19.1 & 1312.9 \\
\hline & $\begin{array}{c}\text { Zonas } \\
\text { inundables }\end{array}$ & 93.5 & 441.1 & 3118.6 & 786.9 & 17.2 & 77.2 & 1372.7 & 5907.3 \\
\hline & Agricultura & 139.8 & 4.8 & 50.2 & 19184.9 & 3.1 & 192.3 & 173 & 19748 \\
\hline & $\begin{array}{l}\text { Vegetación } \\
\text { secundaria }\end{array}$ & 4.7 & 22.6 & 91.2 & 181.3 & 559.8 & 38.2 & 0 & 897.8 \\
\hline & Total & 1128.8 & 4276.5 & 5136.2 & 20703.5 & 738.4 & 1141.3 & 4482 & \\
\hline
\end{tabular}

Los valores en diagonal resaltados representan las superficies en hectáreas que permanecen sin cambio entre 2019 y 2038. Los valores fuera de la diagonal representan las superficies de intercambio durante el mismo periodo. 
TABLA 8. Valores de pérdida, ganancia, cambio neto y permanencia de cobertura y uso de suelo estimados para el periodo $2019-2038$.

\begin{tabular}{|c|c|c|c|c|}
\hline Grupo & $\begin{array}{l}\text { Relación pérdida } \\
\text { permanencia } \\
\qquad l p\end{array}$ & $\begin{array}{l}\text { Relación ganancia } \\
\text { permanencia } \\
g p\end{array}$ & $\begin{array}{c}\text { Relación cambio neto } \\
\text { permanencia } \\
n p\end{array}$ & Permanencia (\%) \\
\hline Manglar & 0.6 & 0.2 & -0.4 & $63.4 \%$ \\
\hline Agricultura & 0.0 & 0.1 & 0.1 & $97.1 \%$ \\
\hline $\begin{array}{l}\text { Vegetación } \\
\text { secundaria }\end{array}$ & 0.6 & 0.3 & -0.3 & $62.4 \%$ \\
\hline Poblados & 0.2 & 0.4 & 0.2 & $83.1 \%$ \\
\hline
\end{tabular}

Los valores de relación pérdida permanencia cercanos a 1 indican una mayor pérdida que permanencia.

Los valores de relación ganancia permanencia cercanos a 1 indican una mayor ganancia que permanencia.

Los valores de relación cambio neto permanencia positivos cercanos a 1 indican una mayor ganancia, los valores negativos cercanos a -1 indican una mayor pérdida.

Es probable que los cambios en la cobertura de mangle estén ligados con impactos a nivel macro en la distribución de agua dulce sobre los canales, resultado de la extracción para estanques acuícolas y agricultura, en conjunto con los cambios en el régimen de lluvia (De la Lanza, Gómez, Blanco, Flores-Verdugo y Hernández, 2010) y la influencia mareal (Blanco, 2012). Si bien, las medidas de restauración del manglar más eficaces han sido aquellas que se centran tanto en la composición vegetal como en el funcionamiento hidrológico (Flores-Verdugo et al., 2007; Flores-Verdugo et al., 2014; Echeverría-Ávila et al., 2019), las medidas de conservación se deben enfocar también en la conservación de sistema hídrico, tomando en cuenta los impactos antrópicos y los cambios derivados de la variabilidad climática tales como: precipitación, ciclones tropicales e incremento del nivel de mar. En este sentido, es esencial regular y mejorar las practicas de la producción acuícola. Como lo explican Lithgow et al. (2019), los impactos son resultado de la falta de conocimiento de los tomadores de decisiones sobre los daños que genera la acuacultura más allá del área de producción inmediata.

\section{CONCLUSIONES}

Se elaboraron dos mapas de cobertura y uso de suelo de los años 2000 y 2019, a partir de una clasificación supervisada de imágenes de satélite, ambas con una exactitud moderada de $71.6 \%$ y $85.7 \%$ de índice Kappa respectivamente. De acuerdo con el mapa del año 2019, los usos predominantes en la llanura costera de San Blas fueron la agricultura con $52.5 \%$ y camaronicultura con $8.5 \%$. La camaronicultura presentó mayor aumento entre el periodo de estudio de 2000-2019, resultando las zonas inundables e indirectamente el manglar las coberturas más afectadas (23.2\% de las zonas inundables que se transformaron a camaronicultura y $24.8 \%$ del manglar a zonas inundables). Este comportamiento ya había sido registrado en periodos pasados desde 1973; el incremento de la construcción de granjas camaroneras se dio entre los años 1997 y 2000 y entre los años 2009 y 2013 según lo documentado por distintos autores (Ortiz y Romo, 1994; Ramírez-García et al., 1998; Hernández et al., 2019). Sin tomar en cuenta generadores de cambio, es probable que esta tendencia se mantenga para el 2038, lo que significaría una reducción de 
$8.3 \%$ de la cobertura manglar entre el 2000 y lo estimado para el 2038.

A decir de otros usos y coberturas durante el periodo de estudio, los poblados registraron poco aumento $(0.6 \%)$, la vegetación secundaria con baja representatividad obtuvo pérdidas por transición a zonas agrícolas de $-0.4 \%$ y las superficies acuáticas mostraron una disminución de $-0.7 \%$, que posiblemente esté relacionado con los periodos mareales y de estiaje. Se observó un cambio en la línea de costa en la desembocadura del río Santiago, lo que figura ser intromisión del mar en área terrestre con una pérdida total de 358.9 ha, entre 2000 y 2019. Se tienen antecedentes de este mismo comportamiento en el periodo 1973-1993 (Ortiz y Romo, 1994; Ramírez-García et al., 1998; Hernández et al., 2019), no obstante, se recomienda realizar estudios puntuales para detectar causas y patrones de variación.

Se debe considerar que la presente es una investigación exploratoria realizada a nivel paisaje, con herramientas de percepción remota, por lo que expone la situación actual de la zona de estudio a través de los resultados obtenidos y los recursos bibliográficos disponibles. Sin embargo, es necesario completar la información y discusión resultante por medio de censos forestales, estudios particulares sobre la estructura de la cobertura manglar y zonas de inundación, con interés por conocer la distribución real de especies, e investigación sobre el sistema hídrico, es decir, captación, flujos, usos, calidad y relación con el movimiento mareal. Asimismo, estudios específicos de la dinámica socioeconómica de la camaronicultura y el turismo que, por ser detonantes de cambio, al incluir información puntual al respecto podría enriquecer la proyección del escenario y las tendencias a futuro de los cambios de uso de suelo en la zona.

Finalmente, como sucede en otras áreas de llanura costera, los cambios en la cobertura de mangle no son provocados directamente por la camaronicultura, pero esta actividad sí genera un impacto sobre el recurso hídrico que repercute en todo el sistema de humedales. Se espera que esta conclusión sea de utilidad para los tomadores de decisiones sobre el desarrollo del área y otras con características similares.

\section{REFERENCIAS}

Aldrich, J. (1997). R. A. Fisher and the making of Maximum Likelihood 1912-1922. Statistical Science, 12(3), 162-176. doi: $10.1214 /$ ss/1030037906

Balzter, H. (2000). Markov chain models for vegetation dynamics. Ecological Modelling, 126(2-3), 139-154. doi: 10.1016/S0304$3800(00) 00262-3$

Berlanga-Robles, C. A., García, R. R., López-Blanco, J., \& Ruiz-Luna, A. (2010). Patrones de cambio de coberturas y usos del suelo en la región costa norte de Nayarit (1973-2000). Investigaciones Geográficas, (72), 7-22. doi: 10.14350/rig.19272

Berlanga-Robles, C. A., \& Ruiz-Luna, A. (2006). Evaluación de cambios en el paisaje y sus efectos sobre los humedales costeros del sistema estuarino de San Blas, Nayarit (México) por medio de análisis de imágenes Landsat. Ciencias Marinas, 32(3), 523-538. doi: $10.7773 / \mathrm{cm} . v 32 \mathrm{i} 3.1126$

Berlanga-Robles, C. A., Ruiz-Luna, A., Bocco, G., \& Vekerdy, Z. (2011). Spatial analysis of the impact of shrimp culture on the coastal wetlands on the northern coast of Sinaloa, Mexico. Ocean \& Coastal Management, 54, 535-543. doi: 10.1016/j.ocecoaman.2011.04.004

Berlanga-Robles, C. A., \& Ruiz-Luna, A. (2013). Integrating remote sensing techniques, Geographical Information Systems (GIS), and Stochastic Models for monitoring Land Use and Land Cover (LULC) changes in the northern coastal region of Nayarit, México. GIScience \& Remote Sensing, 48(2), 245-263. doi: 10.2747/1548-1603.48.2.245

Blanco, M. (2012). Diagnóstico funcional de marismas nacionales: Informe final. Recuperado http://www.conafor.gob.mx:8080/documentos/docs/7/3920D iagn $\% \mathrm{C} 3 \% \mathrm{~B} 3$ stico $\% 20 \mathrm{Funcional} \% 20 \mathrm{de} \% 20$ Marismas $\% 20 \mathrm{Naci}$ onales.pdf

Braimoh, A. K. (2006). Random and systematic land-cover transitions in northern Ghana. Agriculture, Ecosystems and Environment, 113(1-4), 254-263. doi: 10.1016/j.agee.2005.10.019

Brovkin, V., Claussen, M., Driesschaert, E., Fichefet, T., Kicklighter, D., Loutre, M. F., Matthews, H. D., Ramankutty, N., Shaeffer, M., \& Sokolov, A. (2006). Biogeophysical effects of historical land cover changes simulated by six Earth system models of intermediate complexity. Journal Climate Dynamics, 26(6), 587-600. doi: 10.1007/s00382-005-0092-6 
Cohen, J. (1960). A coefficient of agreement of nominal scales. Educational and Pshychological Measurement, 20(1), 37-46. doi: 10.1177/001316446002000104

Congalton, R. G. (1991). A review of assessing the accuracy of classifications of remotely sensed data. Remote Sensing of the Environment, 37(1), 35-46. doi: 10.1016/0034-4257(91)90048-B

Congalton, R. G., \& Green, K. (1993). A practical look at the sources of confusion in error matrix generation. Photogrammetric Engineering and Remote Sensing, 59(5), 641-644.

Comisión Nacional de Áreas Naturales Protegidas [Conanp]. (2008). Sitios Ramsar. Recuperado de https://ramsar.conanp.gob.mx/index.php/sitios-ramsar/

Comisión Nacional Forestal [Conafor]. (2013). Manual comunitarios de restauración de manglares. Recuperado de http://www.conafor.gob.mx:8080/biblioteca/ver.aspx?articulo $=379$

Comisión Nacional para el Conocimiento y Uso de la Biodiversidad [Conabio]. (2007). Los manglares de México: estado actual y establecimiento de un programa de monitorio a largo plazo: $1 \mathrm{ra}$. Etapa. Recuperado de http://www.conabio.gob.mx/conocimiento/manglares/doctos/ Informe_Final_DQ056_31 oct07.pdf

De la Lanza, G., Gómez, J. C., Blanco, M., Flores-Verdugo, F., \& Hernández, S. (2010). Vulnerabilidad costera: caso de estudio del sistema de humedales de Marismas Nacionales. En E. Rivera, I. Azuz, L. Alpuche \& G. Villalobos (Eds.), Cambio climático en México: un enfoque costero y marino (pp. 205-230). México: Universidad Autónoma de Campeche.

Diario Oficial de la Federación [DOF]. (2008). AVISO por el que se informa al público en general que están a su disposición los estudios realizados para justificar la expedición del Decreto por el que se pretende declarar como área natural protegida con el carácter de Área de Protección de Flora y Fauna, la zona conocida como Sistema Singayta, La Tovara y Los Negros, con una superficie de 5,732.54 hectáreas, localizada en el Municipio de San Blas, Estado de Nayarit. Recuperado de http:/ /dof.gob.mx/nota_detalle.php?codigo $=5029328 \&$ fecha $=$ 01/02/2008

Diario Oficial de la Federación [DOF]. (2010). Norma Oficial Mexicana NOM-059-SEMARNAT-2010, Protección ambiental-Especies nativas de México de flora y fauna silvestres-Categorías de riesgo y especificaciones para su inclusión, exclusión o cambio-Lista de especies en riesgo. Recuperado de https://www.profepa.gob.mx/innovaportal/file/3552/1/nom059-semarnat-2010_30-dic-2010.pdf

Echeverría-Ávila, S., Pérez-Ceballos, R., Zaldívar-Jiménez, M., CanalesDelgadillo, J., Brito-Pérez, R., Merino-Ibarra, M., \& Vovides, A.
(2019). Respuesta natural de sitios de manglar degradado en respuesta a la restauración hidrológica. Madera y Bosques, 25(1), 1 14. doi: $10.21829 /$ myb.2019.2511754

Flores-Verdugo, F., Moreno, P., Agraz, C. M., López, H., Benítez, D., \& Travieso, A. C. (2007). La topografía y el hidroperiodo: dos factores que condicionan la restauración de los humedales costeros. Boletin de la Sociedad Botánica de México, (80S), 33-47. doi: 10.17129/botsci.1755

Flores-Verdugo, F., Amezcua, F., Kovacs, J. M., Serrano, D., \& Blanco, M. (2014). Changes in the hydrological regime of coastal lagoons affect mangroves and small scale fisheries: the case of Marismas Nacionales (Pacific coast of Mexico). En F. Amezcua \& B. Bellgrapgh (Eds.), Fisheries Management of Mexican and Central American Estuaries. Estuaries of the World (pp. 81-91). Dordrecht: Springer. doi: 10.1007/978-94-017-8917-2_6

Gallardo, M., \& Martínez-Vega, J. (2012). Cambios de usos del suelo en la comunidad de Madrid: analizando el pasado y simulando el futuro. En J. Martínez-Vega, \& P. Martín (Eds.), Tecnologías de la información geográfica en el contexto de Cambio Global (pp. 305-314). Madrid: Asociación de Geógrafos Españoles.

González, A., Bojórquez, I., Nájera, O., García, D., Madueño, A., \& Flores, F. (2009). Regionalización ecológica de la llanura costera norte de Nayarit, México. Investigaciones Geográficas, (69), 21-32. doi: 10.14350/rig.18002

Hernández-Guzmán, R., Ruiz-Luna, A., \& Cervantes-Escobar A. (2019). Environmental flow assessment for rivers feeding a coastal wetland complex in the Pacific coast of northwest Mexico. Water and Environment Journal, 33(4), 536-546. doi: 10.1111/wej.12423

Instituto Nacional de Estadística y Geografia [Inegi]. (2000). Serie cartográfica de Fisiografía. Escala 1:1 000 000. Recuperado de https://www.inegi.org.mx/app/mapas/

Instituto Nacional de Estadística y Geografía [negi]. (2005). Cartografía digital de vegetación y uso de suelo Serie III. Recuperado de https://www.inegi.org.mx/app/mapas/

Instituto Nacional de Estadística y Geografía [Inegi]. (2010). Censo de población y vivienda 2010. Recuperado de https://www.inegi.org.mx/programas/ccpv/2010/

Instituto Nacional de Estadística y Geografía [Inegi]. (2017). Cartografía digital de vegetación y uso de suelo Serie VI. Recuperado de https://www.inegi.org.mx/app/mapas/

Panel Intergubernamental de Cambio Climático [IPCC]. (2014). Cambio climático 2014. Impactos, adaptación y vulnerabilidad. Resumen para responsables de politicas. Recuperado de https://www.ipcc.ch/site/assets/uploads/2018/03/ar5_wgII_s pm_es-1.pdf 
Landis, J. R., \& Koch, G. G. (1977). The measurement of observer agreement for categorical data. Biometrics, 33(1), 159-174. doi: $10.2307 / 2529310$

Leija-Loredo, E. G., Reyes-Hernández, H., Reyes-Pérez, O., FloresFlores, J. L., \& Sahagún-Sánchez, F. J. (2016). Cambios en la cubierta vegetal de la tierra y escenarios futuros en la región costera del estado de Oaxaca, México. Madera y Bosques, 22(1), 125-140. doi: 10.21829/myb.2016.221481

Lillesand, T., Kiefer, R. W., \& Chipman, J. (2004). Remote sensing and image interpretation (5ta. ed.). Estados Unidos: Wiley.

Lithgow, D., De la Lanza, G., \& Silva, R. (2019). Ecosystem-Based Management strategies to improve aquaculture in developing countries: Case study of Marismas Nacionales. Ecological Engineering, 130, 296-305. doi: 10.1016/j.ecoleng.2017.06.039

López, J., \& Ezcurra, E. (2002). Los manglares de México: una revisión. Madera y Bosques, 8(Es1), 27-51. doi: 10.21829/myb.2002.801290

Martínez-Córdova, L. R., Martínez, M., \& Cortés-Jacinto, E. (2009). Camaronicultura mexicana y mundial: ¿actividad sustentable o industria contaminante?. Revista Internacional de Contaminación Ambiental, 25(3), 181-196.

Mas, J. F. (1999). Monitoring land-cover changes: A comparison of change detection techniques. International Journal of Remote Sensing, 20(1), 139-152. doi: 10.1080/014311699213659

Morales, J. C., Carrillo, F. M., Farfán, L. M., \& Cornejo, V. M. (2016). Cambio de cobertura vegetal en la región de Bahía de Banderas, México. Revista Colombiana de Biotecnología, 3(1), 7-16. doi: 10.15446/rev.colomb.biote.v18n1.57709

Navarro-Rodríguez, M. C., Téllez-López, J., González, L. F., \& CruzRomero, B. (2010). La fragmentación del sistema estuarino de Bahía de Banderas, Jalisco-Nayarit, México. Ciencia y Mar, 14(42), $35-42$.

Ortiz, M. A., \& Pérez, A. (1999). Evidencia documental de los cambios en la línea de costa por sedimentación rápida de la bahía de Matanchén, Nayarit, México. Investigaciones Geográficas, 1(40), 5870. doi: 10.14350/rig.59094

Ortiz, M. A., \& Romo, M. L. (1994). Modificaciones de la trayectoria meándrica en el curso bajo del río grande de Santiago, Nayarit, México. Investigaciones Geográficas, 1(29), 9-23. doi: $10.14350 /$ rig. 59027

Pontius, R. G., Shusas, E., \& McEachern, M. (2004). Detecting important categorical land changes while accounting for persistence. Agriculture, Ecosystems and Environment, 101(2-3), 251268. doi: 10.1016/j.agee.2003.09.008
Ramírez-García, P., López-Blanco, J., \& Ocaña, D. (1998). Mangrove vegetation assessment in the Santiago River Mouth, Mexico, by means of supervised classification using Landsat TM imagery. Forest Ecology and Management, 105(1-3), 217-229. doi: 10.1016/S0378-1127(97)00289-2

Ramos, R. (2015). Potencial y desarrollo turístico de la zona costera del municipio de San Blas, Nayarit. Tesis de Maestría, Universidad Autónoma de Nayarit, Tepic, Nayarit, México.

Reynoso, R., Valdez, J. R., Escalona, M. J., De los Santos, H. M., \& Pérez, M. J. (2016). Cadenas de Markov y autómatas celulares para la modelación de cambio de uso de suelo. Ingeniería bidráulica y ambiental, 37(1), 72-81.

Rodríguez, C. G., Chiriboga, F. G., \& Lojan, A. C. (2016). Las camaroneras ecuatorianas: una polémica medioambiental. Universidad y Sociedad, 8(3), 151-156.

Ruiz, V., Savé, R., \& Herrera, A. (2013). Análisis multitemporal del cambio de uso del suelo, en el Paisaje Terrestre Protegido Miraflor Moropotente Nicaragua, 1993-2011. Ecosistemas, 22(3), 117-123. doi: $10.5377 /$ farem.v0i11.1605

Sanjurjo, E., \& Campos, P. (2011). Análisis de las actividades económicas en un manglar de usos múltiples. Un estudio de caso en San Blas, Nayarit, México. Estudios Sociales, 19(38), 195-220.

Servicio Geológico de los Estados Unidos [USGS] Global Visualization Viewer. Recuperado de https://glovis.usgs.gov

Tovilla, C., \& Orihuela, D. E. (2004). Impacto del huracán Rosa sobre los bosques de manglar de la costa norte de Nayarit, México. Madera y Bosques, 10(Es2), 63-75. doi: $10.21829 /$ myb.2004.1031267

Thomlinson, J. R., Bolstad, P. V., \& Cohen, W. B. (1999). Coordinating methodologies for scaling landcover classifications from sitespecific to global: steps toward validating global map products. Remote Sensing of Environment, 70(1), 16-28. doi: 10.1016/S00344257(99)00055-3

Valdez, J. I. (2002). Aprovechamiento forestal de manglares en el estado de Nayarit, costa Pacífica de México. Madera y Bosques, 8(Es1), 129-145. doi: 10.21829/myb.2002.801296

Valdez, J. I. (2004). Manejo forestal de un manglar al sur de Marismas Nacionales, Nayarit. Madera y Bosques, 10(Es2), 93-104. doi: $10.21829 /$ myb.2004.1031269

Valderrama, L., Troche, C., Rodríguez, M., Márquez, D., Vázquez, B., Velázquez, S., Vázquez, A., Cruz, M., \& Ressl, R. (2014). Evaluation of mangrove cover changes in Mexico during the 1970-2005 period. Wetlands, 34(4), 747-758. doi: 10.1007/s13157014-0539-9 
Yáñez-Arancibia, A., Twilley, R. R., \& Lara-Domínguez, A. L. (1998). Los ecosistemas de manglar frente al cambio climático global. Madera y Bosques, 4(2), 3-19. doi: 10.21829/myb.1998.421356

Yáñez-Arancibia, A., Day, J. W., Twilley, R. R., \& Day, R. H. (2014). Manglares: ecosistemas centinela frente al cambio climático, Golfo de México. Madera y Bosques, 20(Es), 39-75. doi: $10.21829 /$ myb.2014.200147

Manuscrito recibido el 18 de enero de 2020

Aceptado el 06 de mayo de 2020

Publicado el 19 de marzo dd 2021
Este documento se debe citar como:

Nájera González, A., Carrillo González, F. M., Morales Hernández, J. C., \& y Nájera González, O. (2021). Cambio de cobertura y uso de suelo en la llanura costera asociados a procesos antropogénicos: caso San Blas, Nayarit. Madera y Bosques, 27(1), e2712104. doi: 10.21829/myb.2021.2712104

Madera y Bosques por Instituto de Ecología, A.C. se distribuye bajo una Licencia Creative Commons Atribución-NoComercialCompartirlgual 4.0 Internacional. 